\title{
The clinical use of the platelet to lymphocyte ratio and lymphocyte to monocyte ratio as prognostic factors in renal cell carcinoma: a systematic review and meta-analysis
}

\author{
Xuemin Wang ${ }^{1}$, Shiqiang Su${ }^{1}$ and Yuanshan Guo ${ }^{1}$ \\ ${ }^{1}$ Department of Urology, The First Hospital of Shijiazhuang, Shijiazhuang 050011, Hebei Province, China \\ Correspondence to: Xuemin Wang, email: xueminWANG66@163.com \\ Keywords: inflammation, platelet to lymphocyte ratio, lymphocyte to monocyte ratio, renal cell carcinoma, prognosis \\ Received: August 08, $2017 \quad$ Accepted: September 03, $2017 \quad$ Published: September 20, 2017 \\ Copyright: Wang et al. This is an open-access article distributed under the terms of the Creative Commons Attribution License 3.0 (CC BY \\ 3.0), which permits unrestricted use, distribution, and reproduction in any medium, provided the original author and source are credited.
}

\section{ABSTRACT}

Conflicting evidence exists regarding the effect of platelet to lymphocyte ratio (PLR) and lymphocyte to monocyte ratio (LMR) on the prognosis of renal cell carcinoma (RCC) patients. Here we quantify the prognostic impact of these biomarkers and assess their consistency in RCC. Eligible studies were retrieved from the PubMed, Embase and Web of Science databases. Pooled hazard ratios (HRs), odds ratios (ORs), and $95 \%$ confidence intervals (CIs) were calculated. Sixteen studies containing 6,223 patients met criteria for inclusion. Overall, elevated PLR was associated with poorer overall survival (OS, HR 1.76, 95\% CI 1.41-2.19, $P<0.001$ ), progression-free survival (PFS, HR 2.81, 95\% CI 1.40-5.63, $P=0.004$ ) and recurrence-free survival (RFS, HR 2.64, 95\% CI 1.35-5.14, $P=0.004)$. Conversely, high LMR was correlated with more favorable OS (HR 0.62, 95\% CI 0.51-0.77, P< 0.001) and RFS (HR 0.53, 95\% CI $0.42-0.67, P<0.001$ ). Moreover, low LMR was significantly associated with some clinicopathological characteristics that are indicative of poor prognosis and disease aggressiveness. By these results, elevated PLR was associated with poor outcomes, while high LMR correlated with more favorable survival in RCC patients. Pretreatment PLR and LMR can serve as prognostic factors in RCC patients.

\section{INTRODUCTION}

Renal cell carcinoma (RCC), the seventh most common cancer for male and the ninth for female worldwide, represents $2-3 \%$ of all malignances in adults [1]. According to estimates, there will be 66,800 new confirmed cases and 23,400 occurred deaths in China in 2015 [2]. Despite great progress in surgical procedures, immune-therapy and targeted treatment in managing renal mass, its long-term survival remains unsatisfactory largely because of common recurrence in situ, distant metastasis and poor response rate [3]. The identification of prognosis predictors may have clinical significance to instruct therapeutic decisions and follow-up arrangements. Although postoperative histopathological variables are presently the most widespread accepted factors for patients stratification [4], these parameters may not be thoroughly dependable. Additionally, since most prognosis predictors are assessed postoperatively, preoperative biomarkers are needed to early predict oncologic outcomes.
More and more evidence supports that inflammation exerts a crucial role in the pathogenesis and progression of various malignances, including RCC [5-7]. Systemic inflammatory response (SIR) is well-agreed to be reflected by many biochemical or hematological parameters. Circulating biomarkers, which stand for the condition of inflammation, are believed to be potential prognostic factors for RCC patients. Platelet to lymphocyte ratio (PLR), and lymphocyte to monocyte ratio (LMR), two inflammatory markers which are came from the blood cells, have gained prognostic value in in a number of malignant diseases, including RCC $[8,9]$. These two biomarkers, are non-invasive and simple, which may be easily accessible prognosis predictors that could be applied to instruct clinical decisions. A number of researches have examined their role as prognosis predictors, nevertheless, the coherence and importance of the prognostic value of PLR and LMR are still needed to be explored.

Hence, a systematic review of the related literatures was performed to investigate the associations 
of pretreatment PLR and LMR in RCC patients with oncologic outcomes and to combine the results in a metaanalysis.

\section{RESULTS}

\section{Search results}

A flow diagram of the study search process is presented in Figure 1. Totally, 85 records were identified through the primary study searching. Of all identified records, 29 were excluded due to duplicate studies. After screening the titles and abstracts, 20 literatures were remained. Then full-text screening was performed, 4 literatures were excluded because of overlapped records and out of scope. Finally, 16 literatures containing totally 6,223 patients, were included according to the eligibility criteria [10-25]. Among these literatures, 8 studied PLR, 5 investigated LMR, and 3 assessed both PLR and LMR.

\section{Characteristics of the studies}

The baseline characteristics of the 16 literatures are outlined in Table 1. Most of the included studies had a retrospective design. All of them were published recently (2013-2017). Patients number ranged from 53 to 1360.
The median or mean age of patients ranged from 55 to 65.5 years. Five literatures included all stages RCC, 7 studies only included metastatic RCC, and 4 studies only included non-metastatic RCC. Nine studies included all types RCC, 7 studies only included clear cell RCC. In 9 studies, the HR was adjusted for other covariates including histology, lymph node metastasis status, tumor stage, tumor site and size, Fuhrman grade, and tumor necrosis.

\section{Impact of PLR in OS, PFS and RFS of RCC patients}

The association between PLR and oncologic outcomes was reported in 11 studies enrolling 3,660 patients $[10-12,14,15,17-19,22,24,25]$. Of these studies, 10 reported the results of overall survival (OS), 4 reported the results of progression-free survival (PFS), 1 reported the results of recurrence-free survival (RFS). Since significant heterogeneity exists among studies, a random-effect model was used in the analyses $\left(\mathrm{I}^{2}=55.5 \%\right.$ and $87.2 \%, P=0.017$ and $<0.001)$. As shown in Figure 2 , after merging the data, we found that a high PLR was related to shorted OS (hazard ratio [HR] 1.76, 95\% confidence interval [CI] 1.41-2.19, $P<0.001$ ), and PFS (HR 2.81, 95\% CI 1.40-5.63, $P=0.004$ ). In addition, Lucca et al. [18] identified that patients with a high PLR

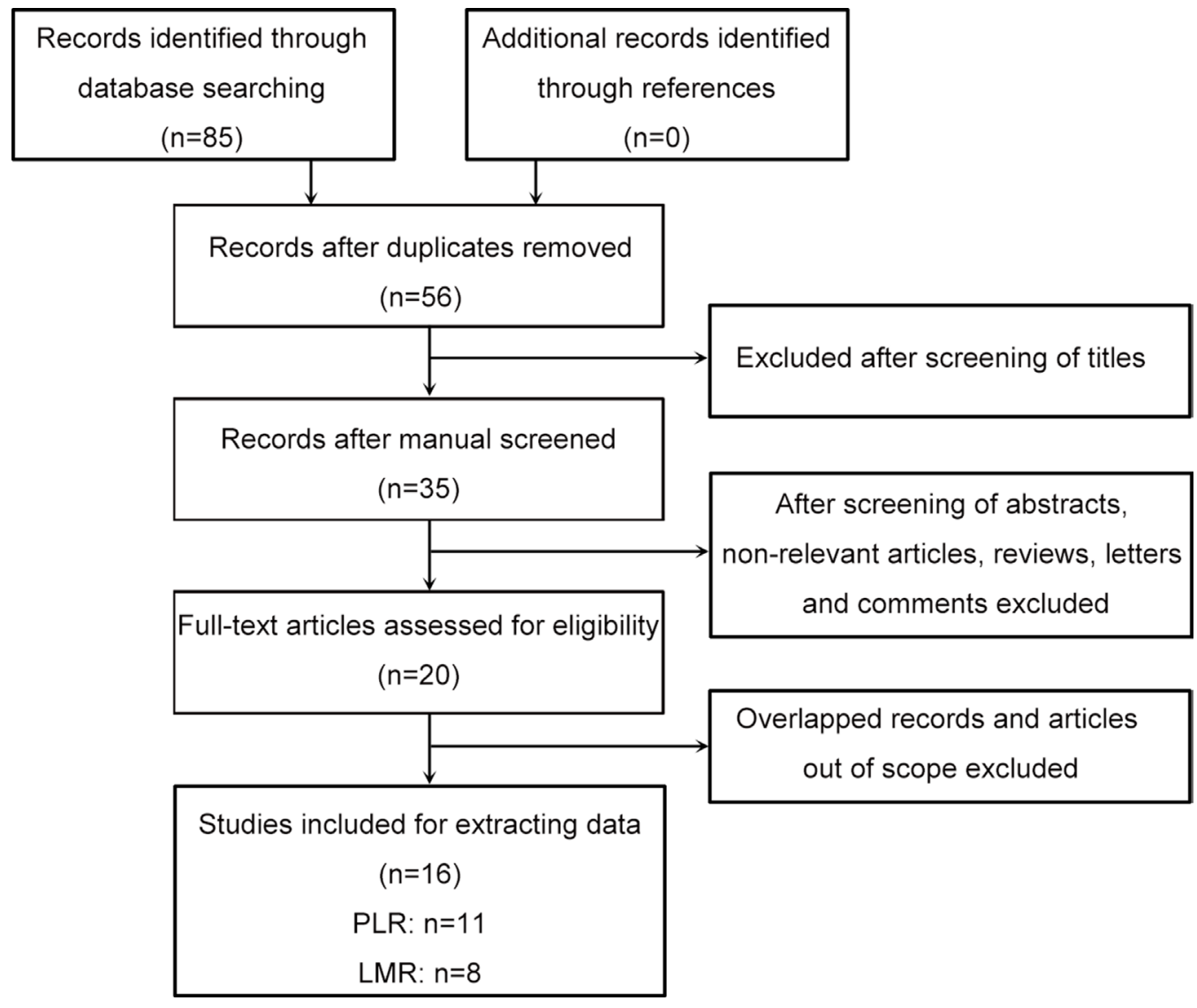

Figure 1: Flowchart shows the selection of literature for meta-analysis. 
Table 1: Baseline characteristics of studies included in this meta-analysis

\begin{tabular}{|c|c|c|c|c|c|c|c|c|c|c|c|c|}
\hline Study (year) & Country & $\begin{array}{l}\text { Study } \\
\text { design }\end{array}$ & Stage & Histology & $\begin{array}{c}\text { Sample } \\
\text { size }\end{array}$ & Median age & $\begin{array}{c}\text { Cut-off } \\
\text { value }\end{array}$ & $\begin{array}{c}\text { Determine } \\
\text { the cut-off } \\
\text { value }\end{array}$ & $\begin{array}{l}\text { Survival } \\
\text { analysis }\end{array}$ & $\begin{array}{c}\text { Source } \\
\text { of HR }\end{array}$ & Adjusted & $\begin{array}{c}\text { Follow-up } \\
\text { (months) }\end{array}$ \\
\hline Peng 2017 & China & $\mathrm{R}$ & All & All & 1360 & $55(14-87)$ & $\begin{array}{c}\text { PLR: } \\
\text { 164/176 } \\
\text { LMR: } 4.3\end{array}$ & ROC analysis & OS, PFS & $\mathrm{SC}$ & No & $2-108$ \\
\hline Ishihara 2017 & Japan & $\mathrm{R}$ & M & All & 63 & - & PLR: 183 & $\begin{array}{l}\text { Maximum } \\
\text { Youden index }\end{array}$ & OS, PFS & Rep & Yes & -60 \\
\hline Chrom 2017 & Poland & $\mathrm{R}$ & M & All & 321 & $62(22-85)$ & PLR: 157 & $\begin{array}{l}\text { IMDC } \\
\text { criteria }\end{array}$ & OS & Rep & Yes & -72 \\
\hline Xia 2016 & China & $\mathrm{R}$ & NM & Clear cell & 985 & $55(21-81)$ & LMR: 3.0 & $\begin{array}{c}25 \text { th } \\
\text { percentile }\end{array}$ & OS, RFS & $\mathrm{DE}$ & No & $3-60$ \\
\hline Park 2016 & Korea & $\mathrm{R}$ & M & Clear cell & 63 & $\begin{array}{c}63.1 \\
(56-70.5)\end{array}$ & PLR: 150 & ROC analysis & OS, PFS & Rep & Yes & - \\
\hline Hu 2016 & China & $\mathrm{R}$ & All & All & 484 & $56(21-81)$ & PLR: 185 & ROC analysis & OS & Rep & Yes & -60 \\
\hline Gu 2016 & China & $\mathrm{R}$ & M & Clear cell & 145 & $56(47-63)$ & LMR: 3.0 & ROC analysis & OS, PFS & Rep & Yes & -60 \\
\hline Gu 2016 & China & $\mathrm{R}$ & All & All & 103 & $56(16-79)$ & $\begin{array}{l}\text { PLR: } 132 \\
\text { LMR: } 3.1\end{array}$ & ROC analysis & OS & Rep & Yes & -110 \\
\hline Lucca 2015 & Austria & $\mathrm{R}$ & NM & Clear cell & 430 & $65.5(57-73)$ & $\begin{array}{l}\text { PLR: } 145 \\
\text { LMR: } 2.5\end{array}$ & $\begin{array}{c}\text { Maximum } \\
\text { survival } \\
\text { difference }\end{array}$ & RFS & Rep & Yes & -48 \\
\hline Gunduz 2015 & Turkey & $\mathrm{R}$ & M & All & 94 & $58(33-95)$ & PLR: 210 & $\begin{array}{c}\text { Maximum } \\
\text { survival } \\
\text { difference }\end{array}$ & OS, PFS & $\mathrm{SC}$ & No & -40 \\
\hline Chang 2015 & China & $\mathrm{R}$ & NM & Clear cell & 430 & $56(46-63)$ & LMR: 3.25 & $\begin{array}{c}25 \text { th } \\
\text { percentile }\end{array}$ & RFS & Rep & Yes & -72 \\
\hline Chang 2015 & China & $\mathrm{R}$ & All & Clear cell & 441 & $56(46-63)$ & LMR: 4.44 & Median & OS & $\mathrm{SC}$ & No & -72 \\
\hline Keskin 2014 & Turkey & $\mathrm{R}$ & All & All & 211 & $61.2(11.8)^{\mathrm{a}}$ & PLR: 151 & Median & OS & $\mathrm{SC}$ & No & -24 \\
\hline Hutterer 2014 & Austria & $\mathrm{R}$ & NM & Clear cell & 678 & $65(20-88)$ & LMR: 3.0 & ROC analysis & OS, RFS & Rep & Yes & $0-130$ \\
\hline Fox 2013 & Australia & $\mathrm{P}$ & M & All & 362 & $62(19-84)$ & PLR: 195 & Median & OS & Rep & No & -40 \\
\hline Dirican 2013 & Turkey & $\mathrm{R}$ & M & All & 53 & $61(40-79)$ & PLR: 134 & $\begin{array}{l}\text { Regression } \\
\text { tree analysis }\end{array}$ & OS & $\mathrm{DE}$ & No & -40 \\
\hline
\end{tabular}

Notes: study design: R retrospective, P prospective. Stage: All non-metastatic and metastatic, M metastatic, NM non-metastatic. Histology: All clear cell and non-clear cell. Surviva analysis: OS overall survival, PFS progression-free survival, RFS recurrence-free survival. Source of HR: SC survival curve, Rep reported, DE data extrapolated.

- , not reported.

${ }^{\mathrm{a}}$ shown as mean $(\mathrm{SD})$

experienced a shorter RFS (HR 2.64, 95\% CI 1.35-5.14, $P=0.004)$. According to subgroup analysis, the HR of PLR on overall survival was 1.43 (95\% CI 1.20-1.69, $P<$ 0.001 ) for all stage (non-metastatic and metastatic) RCC, and 1.97 (95\% CI 1.44-2.70, $P<0.001)$ for metastatic RCC patients. According to meta-regression analysis, year of publication, geographic region, cancer stage, sample size, cut-off value, source of HR, and ROC curve did not significantly contribute to inter-study heterogeneity $(P=$ 0.178-0.786) (Table 2). According to sensitivity analysis, getting rid of any single literature did not significantly alter the pooled HR.

\section{Impact of LMR in OS, PFS and RFS of RCC patients}

The relationship between LMR and oncologic outcomes was described in 8 literatures containing 4,572 patients $[10,13,16-18,20,21,23]$. Of these studies, 6 reported the results of OS, 2 reported the results of PFS, 4 reported the results of RFS. As shown in Figure 3, after merging the data, we found that a high LMR was associated with superior OS (HR 0.62, 95\% CI 0.51-0.77, $P<0.001$ ) and RFS (HR 0.53, 95\% CI 0.42-0.67, $P<$ $0.001)$. However, the association between an elevated LMR and PFS (HR 0.57, 95\% CI 0.32-1.04, $P=0.065$ ) did not obtain significance. According to subgroup analysis, the HR of LMR on overall survival was 0.75 (95\% CI 0.63-0.89, $P=0.001$ ) for all types (clear cell and non-clear cell) RCC, and 0.54 (95\% CI 0.44-0.68, $P$ $<0.001$ ) for clear cell RCC patients. According to metaregression analysis, year of publication, histology, sample size, cut-off value, source of HR, and ROC curve did not significantly contribute to inter-study heterogeneity $(P=$ $0.082-0.779$ ) (Table 2). According to sensitivity analysis, getting rid of any single literature did not significantly alter the pooled HR.

\section{The relationship between LMR and clinicopathological characteristics}

Four studies reported adequate data for the metaanalysis. As presented in Table 3, a high LMR was of a significant correlation with Fuhrman grade (III/IV vs I/II: odd 


\begin{tabular}{|c|c|c|c|c|c|}
\hline \multirow{2}{*}{ Subgroup } & \multirow{2}{*}{ HR (95\% CI) } & \multirow{2}{*}{$P$ value } & \multirow{2}{*}{$\begin{array}{c}\text { Meta-regression } \\
P \text { value }\end{array}$} & \multicolumn{2}{|c|}{ Heterogeneity } \\
\hline & & & & $I^{2}(\%)$ & $P$ value \\
\hline & & PLR & & & \\
\hline Year of publication & & & 0.284 & & \\
\hline 2016-2017 & $1.78(1.23-2.57)$ & 0.002 & & 67.8 & 0.008 \\
\hline $2013-2015$ & $1.86(1.53-2.25)$ & $<0.001$ & & 0.0 & 0.635 \\
\hline Region & & & 0.295 & & \\
\hline Asia & $2.00(1.15-3.47)$ & 0.014 & & 73.7 & 0.004 \\
\hline Non-Asia & $1.80(1.52-2.12)$ & $<0.001$ & & 0.0 & 0.709 \\
\hline Stage & & & 0.178 & & \\
\hline Mixed & $1.43(1.20-1.69)$ & $<0.001$ & & 19.4 & 0.293 \\
\hline Metastatic & $1.97(1.44-2.70)$ & $<0.001$ & & 58.5 & 0.034 \\
\hline Sample size & & & 0.726 & & \\
\hline$>200$ & $1.60(1.40-1.82)$ & $<0.001$ & & 37.2 & 0.174 \\
\hline$<200$ & $2.17(1.18-3.99)$ & 0.012 & & 70.1 & 0.010 \\
\hline Cut-off value & & & 0.653 & & \\
\hline$>160$ & $1.59(1.39-1.82)$ & $<0.001$ & & 18.5 & 0.297 \\
\hline$<160$ & $2.22(1.24-3.99)$ & 0.007 & & 72.8 & 0.007 \\
\hline ROC curve & & & 0.240 & & \\
\hline Considered & $1.96(1.04-3.66)$ & 0.036 & & 78.8 & 0.003 \\
\hline Not considered & $1.81(1.54-2.13)$ & $<0.001$ & & 0.0 & 0.774 \\
\hline Analysis of hazard ratio & & & 0.786 & & \\
\hline Univariate & $1.60(1.40-1.83)$ & $<0.001$ & & 37.6 & 0.171 \\
\hline Multivariable & $2.12(1.21-3.71)$ & 0.009 & & 70.4 & 0.009 \\
\hline & & $L M R$ & & & \\
\hline Year of publication & & & 0.771 & & \\
\hline 2016-2017 & $0.68(0.59-0.80)$ & $<0.001$ & & 44.7 & 0.143 \\
\hline 2014-2015 & $0.58(0.35-0.96)$ & 0.032 & & 60.3 & 0.112 \\
\hline Histology & & & 0.099 & & \\
\hline Mixed & $0.75(0.63-0.89)$ & 0.001 & & 0.0 & 0.657 \\
\hline Clear cell & $0.54(0.44-0.68)$ & $<0.001$ & & 12.3 & 0.331 \\
\hline Sample size & & & 0.365 & & \\
\hline$>600$ & $0.70(0.60-0.82)$ & $<0.001$ & & 31.4 & 0.233 \\
\hline$<600$ & $0.54(0.39-0.73)$ & $<0.001$ & & 39.7 & 0.190 \\
\hline Cut-off value & & & 0.515 & & \\
\hline$>3.0$ & $0.66(0.47-0.93)$ & 0.017 & & 52.6 & 0.121 \\
\hline$=3.0$ & $0.58(0.45-0.74)$ & $<0.001$ & & 20.1 & 0.286 \\
\hline ROC curve & & & 0.082 & & \\
\hline Considered & $0.72(0.62-0.84)$ & $<0.001$ & & 0.0 & 0.399 \\
\hline Not considered & $0.48(0.35-0.65)$ & $<0.001$ & & 0.0 & 0.665 \\
\hline Analysis of hazard ratio & & & 0.779 & & \\
\hline Univariate & $0.64(0.45-0.92)$ & 0.016 & & 64.9 & 0.091 \\
\hline Multivariable & $0.61(0.47-0.77)$ & $<0.001$ & & 37.5 & 0.187 \\
\hline
\end{tabular}

HR, hazard ratio; CI, confidence interval. PLR, platelet to lymphocyte ratio. LMR, lymphocyte to monocyte ratio. 
Table 3: Meta-analysis of the association between elevated LMR and clinicopathological features of renal cell carcinoma

\begin{tabular}{llllllll}
\hline \multicolumn{1}{c}{ Variables } & Studies & Patients & Pooled OR & $\mathbf{9 5 \%}$ CI & $\boldsymbol{P}$ value & $\begin{array}{c}\text { Heterogeneity } \\
\boldsymbol{I}(\mathbf{\%})\end{array}$ & $\boldsymbol{P}$ value \\
\hline Fuhrman grade & 3 & 1264 & 0.63 & $0.53-0.76$ & $<0.001$ & 0.0 & 0.463 \\
Tumor necrosis & 3 & 1264 & 0.66 & $0.54-0.79$ & $<0.001$ & 7.4 & 0.340 \\
Tumor size & 2 & 1426 & 0.59 & $0.51-0.69$ & $<0.001$ & 0.0 & 0.418 \\
pT stage & 3 & 1808 & 0.60 & $0.49-0.73$ & $<0.001$ & 0.0 & 0.587 \\
Lymph node status & 2 & 1130 & 0.60 & $0.18-2.00$ & 0.410 & 65.6 & 0.088 \\
TNM staging & 2 & 1426 & 0.61 & $0.26-1.41$ & 0.245 & 89.7 & 0.002 \\
\hline
\end{tabular}

LMR, lymphocyte to monocyte ratio. OR, odd ratio. CI, confidence interval.

ratio [OR] $0.63,95 \% \mathrm{CI} 0.53-0.76, P<0.001)$, tumor necrosis (present vs absent: OR 0.66, 95\% CI $0.54-0.79, P<0.001$ ), tumor size ( $>7$ vs $<=7$ : OR $0.59,95 \%$ CI $0.51-0.69, P<$ $0.001)$, pT stage (pT3-4 vs pT1-2: OR 0.60, 95\% CI 0.49 $0.73, P<0.001)$. Nevertheless, the correlation between a high LMR and lymph node status (positive vs negative: OR 0.60, 95\% CI 0.18-2.00, $P=0.410$ ), TNM staging (III/IV vs I/II: OR $0.61,95 \%$ CI $0.26-1.41, P=0.245)$ was not significant.

\section{Publication bias}

In the literatures of correlations between PLR and LMR with overall survival in RCC, the funnel plots seem to be symmetry (Figure 4). The Egger's and Begg's tests were further performed. The results indicated absent evidence of significant publication bias for literatures about PLR and merged OS (Begg's test, $P=0.210$; Egger's test, $P=0.095$ ), and studies concerning LMR and pooled OS (Begg's test, $P$ = 0.707; Egger's test, $P=0.221$ ).

\section{DISCUSSION}

Presently, the identification of prognostic biomarkers mainly focuses on tumor self- presentation and biological behavior, which might not stand for the authentic burden of RCC. The inclusion of the peripheral blood biomarkers

\begin{tabular}{|c|c|c|c|}
\hline $\begin{array}{l}\text { Study } \\
\text { ID }\end{array}$ & & $\mathrm{HR}(95 \% \mathrm{Cl})$ & $\begin{array}{l}\% \\
\text { Weight }\end{array}$ \\
\hline \multicolumn{4}{|l|}{ os } \\
\hline Peng (2017) & $\rightarrow$ & $1.38(1.14,1.67)$ & 19.66 \\
\hline Ishihara (2017) & & $2.51(0.91,7.58)$ & 3.63 \\
\hline Chrom (2017) & $\rightarrow$ & $1.63(1.18,2.28)$ & 15.21 \\
\hline Park (2016) & & $16.12(4.40,58.40)$ & 2.57 \\
\hline $\mathrm{Hu}(2016)$ & $\rightarrow$ & $1.63(0.88,3.05)$ & 8.12 \\
\hline Gu (2016) & 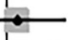 & $1.17(0.62,2.22)$ & 7.85 \\
\hline Gunduz (2015) & $\rightarrow$ & $1.68(1.12,2.53)$ & 12.88 \\
\hline Keskin (2014) & 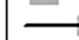 & $3.00(1.30,6.92)$ & 5.33 \\
\hline Fox (2013) & $\rightarrow$ & $1.88(1.49,2.38)$ & 18.29 \\
\hline Dirican (2013) & $\rightarrow$ & $1.57(0.75,3.26)$ & 6.46 \\
\hline Subtotal (I-squared $=55.5 \%, p=0.017$ ) & $\diamond$ & $1.76(1.41,2.19)$ & 100.00 \\
\hline \multicolumn{4}{|l|}{ PFS } \\
\hline Peng (2017) & $\rightarrow$ & $1.40(1.15,1.72)$ & 30.84 \\
\hline Ishihara (2017) & & $2.80(1.15,7.22)$ & 20.43 \\
\hline Park (2016) & & $13.07(5.14,33.20)$ & 20.21 \\
\hline Gunduz (2015) & & $1.99(1.32,3.00)$ & 28.52 \\
\hline Subtotal ( 1 -squared $=87.2 \%, p=0.000)$ & & $2.81(1.40,5.63)$ & 100.00 \\
\hline \multicolumn{4}{|l|}{ RFS } \\
\hline Lucca (2015) & & $2.64(1.36,5.16)$ & 100.00 \\
\hline Subtotal $(\mathrm{I}$-squared $=. \%, p=)$. & & $2.64(1.35,5.14)$ & 100.00 \\
\hline \multicolumn{4}{|c|}{ NOTE: Weights are from random effects analysis } \\
\hline 1 & & & \\
\hline .0171 & 1 & & \\
\hline
\end{tabular}

Figure 2: Forest plot reflects the association between PLR and oncologic outcomes. OS $=$ overall survival, $\mathrm{PFS}=$ progressionfree survival, RFS = recurrence-free survival. 
as complementary items to existing prognosis prediction model is helpful in guiding clinical treatment strategy. Recent studies have identified that the markers of SIR are of prognostic significance in various cancer [8, 9, 26, 27]. Nevertheless, the coherence and importance of the prognostic value of PLR and LMR are still needed to be explored.

Hence, a systematic review of related literatures was conducted to assess the prognostic role of PLR and LMR in RCC. Then quantitative synthesis was performed using data from 16 studies embracing 6,223 patients. In the present study, we found that pretreatment PLR and LMR can be applied as prognostic factors for RCC cases. A high PLR was correlated with inferior OS, poor PFS and unfavorable RFS. To the contrary, a decreased LMR was associated with poor OS and RFS, but not for PFS. Moreover, subgroup analyses by year of publication, region, stage, histology, sample size, cut-off value, ROC curve, and source of HR did not affect the impact of PLR and LMR on OS. Our findings also showed that RCC cases having decreased LMR are prone to experience a higher nuclear grade, tumor necrosis, a larger primary tumor size, and a higher pathological T stage. Since there were no more than two studies report the same variables, we didn't merge the data about the associations between PLR and clinicopathological parameters. As PLR and LMR measurements are simple and easily accessible in each clinical centers, they can be useful and convenient circulating markers for decision-making.
The potential mechanisms of altered PLR and LMR affecting the oncologic outcomes of RCC patients remain speculative at this time. Elevated platelet count is commonly identified in patients with malignance, and is related to inferior oncologic outcomes [27]. Platelets may protect cancer cells from detecting or attacking by the autoimmune system. The potential mechanisms include platelets promote tumor cell adhesion to the vascular endothelium, or interact with cancer cells through its ligands [28]. Orellana et al. [29] cultivated human platelets and ovarian tumor cells together, and identified that interactions between platelet and cancer cell promoted metastasis formation. Moreover, obstruction of key platelet receptors hindered metastasis formation. Lymphopenia is an important component of elevated PLR. Lymphocytes stand for the cellular basis of immune-surveillance and immune-modifying, and lymphocyte penetration into the microenviroment of cancer act as a prior condition for the immune response against cancer [30, 31]. A low lymphocyte count might result in attenuation of immunologic antitumor reaction. However, monocytes infiltrating tumor microenviroment have a role in tumor development and progression [5]. Monocytes may be closely associated with the formation of tumor-associated macrophages (TAMs). More and more evidence supported that the TAMs enhance tumor progression. Based on these data, it is understandable that an elevated PLR and/or a decreased LMR lead to inferior survival.

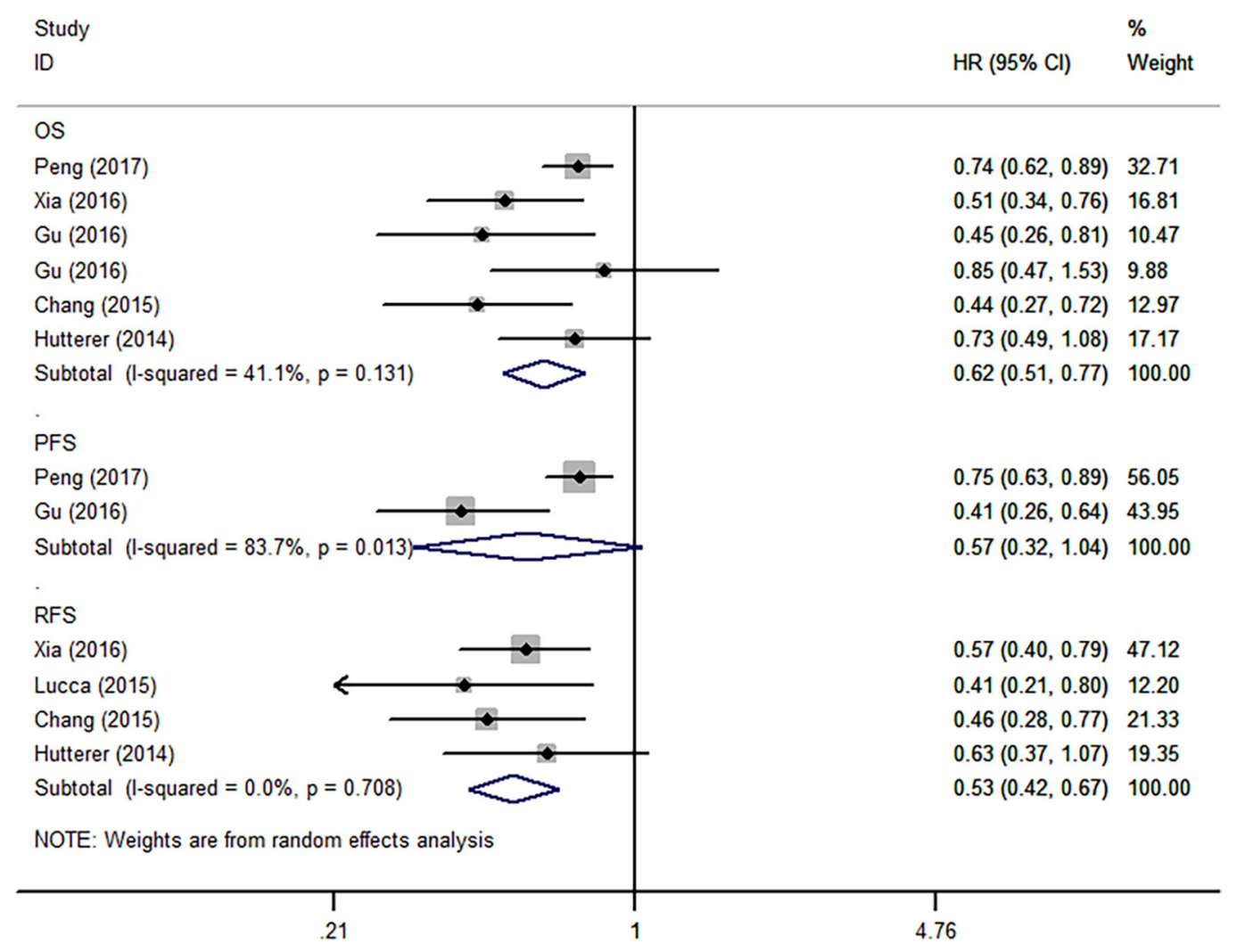

Figure 3: Forest plot reflects the association between LMR and oncologic outcomes. OS $=$ overall survival, PFS $=$ progressionfree survival, RFS = recurrence-free survival. 
Several underlying limitations of the present study should be admitted. First, though 16 literatures of 6,223 subjects were included in the present metaanalysis, only 11 articles studied PLR and 8 articles studied LMR. Due to the limited literatures, we analyzed metastatic and non-metastatic RCC together, which may introduce some inter-study heterogeneity. Second, obvious heterogeneity of studies was observed in several analyses. The inter-literatures heterogeneity was possibly because of differences in patients' features (country, race, age, stage and histology), duration of follow-up, and the inconsistency of PLR and LMR cutoff values. Additionally, the type of HR and approach of calculating the hazard ratios also may result in heterogeneity. Of the 16 literatures, 10 reported HRs directly, and each HRs of the residual literatures were figured up with the methods described by Tierney et al. [32]. Among the 10 studies providing HRs, one reported univariate hazard ratio, which did not adjust for the potential confounding factors [24].

All included literatures were published in 2013 or later, indicating the present focus in studying the prognostic roles of PLR and LMR in RCC. Despite the above limitations, this systematic review and meta-analysis represents the most informative and comprehensive study evaluating this topic. Based on our findings, a high PLR was correlated with inferior outcomes, while elevated LMR was associated with relatively superior survival in RCC patients. The relative availability and low cost of these biomarkers should facilitate their use in predicting prognosis for RCC patients.

\section{MATERIALS AND METHODS}

\section{Literature search}

The databases of PubMed, Embase and Web of Science were methodically searched for article up to July 2017. The major searching terms included: "renal",

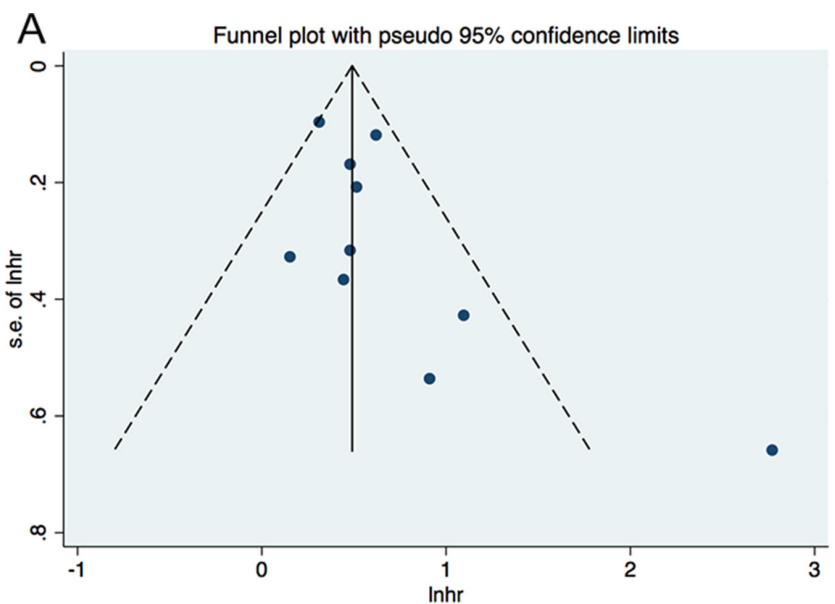

"cancer", "platelet to lymphocyte ratio", "lymphocyte to monocyte ratio" and "prognosis". Additionally, we manually searched the bibliographies of relevant literatures for additional eligible studies.

\section{Study selection}

The primary criteria weighed in including a literature were studying the oncologic outcomes of RCC, using pretreatment PLR or LMR as prognostic indicators and investigating their association with survival outcomes including OS, RFS and PFS. Articles were excluded if they (a) were presented in non-English; (b) were short of adequate data for calculating HRs and their 95\% CIs; (c) reported PLR or LMR as continuous variables; (d) studied post-treatment PLR or LMR. When one center published more than one article about the same study population, we just included the most comprehensive and latest study. Two reviewers independently considered all the articles that met the inclusion criteria for full-text review. Any disagreements were discussed and arbitrated by a third reviewer.

\section{Data extraction and synthesis}

According to the current interest, OS was the primary outcome, RFS and PFS were secondary outcomes. Two researchers independently collected necessary data. The data needs to be extracted as following: publication information (first author's last name, year of publication, geographic region, and study design), patients' characteristics (sample size, age, follow-up time), cancer and outcomes (cancer stage, histology, oncologic outcomes, source of HR, adjusted or not), PLR or LMR data (cut-off value, the determining method). HRs of PLR or LMR for OS, RFS, PFS, as well as their 95\% CIs were also extracted. If possible, HRs were obtained from multivariable analyses in prior. If not, HRs were obtained from univariate analyses. If the study did not provide HRs directly, we estimated individual HRs with the reported

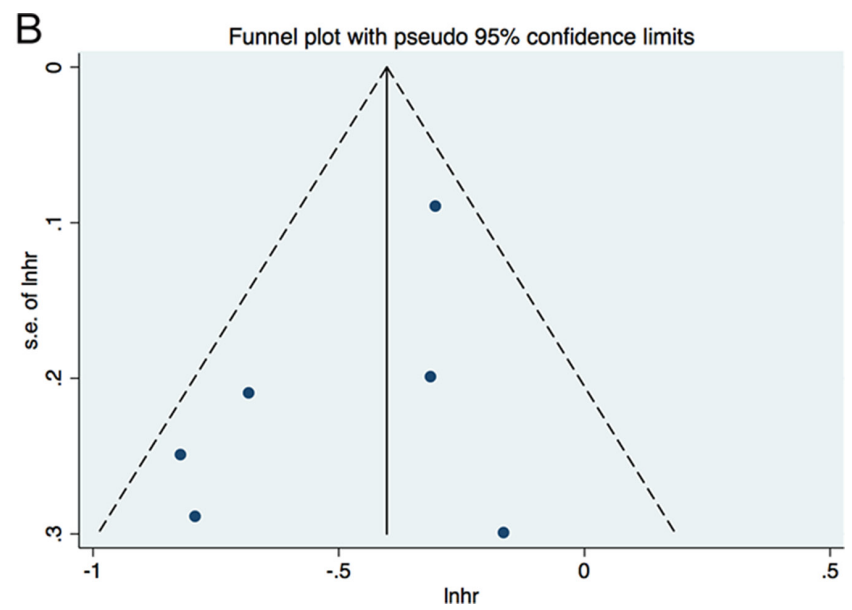

Figure 4: Funnel plot for publication bias. (A) correlation of PLR with OS; (B) correlation of LMR with OS 
data (Kaplan-Meier curves or the necessary data) by applying the methods described by Tierney et al. [32] Subgroup analyses for OS were also performed to explore source of heterogeneity. The variables included year of publication, region, stage, histology, sample size, cut-off value, ROC curve, and source of HR.

We also studied the associations between LMR and clinicopathological parameters of RCC. Information about Fuhrman grade (III/IV vs I/II), tumor necrosis (present vs absent), tumor size ( $>7 \mathrm{vs}<=7$ ), pT stage (pT3-4 vs pT1-2), lymph node status (positive vs negative), TNM staging (III/IV vs I/II) were dichotomized. The event numbers were obtained from original studies, and the ORs and corresponding 95\% CIs were calculated.

\section{Statistical analysis}

Inter-study heterogeneity was measured by performing Cochran's $Q$ test and Higgins I-squared statistic. There was marked heterogeneity if the $P$ value was less than 0.10 and $/$ or $\mathrm{I}^{2}>50 \%$. When the heterogeneity was identified, a random-effect model was applied. Otherwise, we used a fixed-effect model. A merged HR greater than 1 indicated a poor survival for the patients with a high PLR or LMR. The reasons for inter-study heterogeneity were also explored by using subgroup and meta-regression analysis. We evaluated publication bias with visual examination of funnel plots and precisely assessed by Egger's and Begg's tests when 6 and more literatures were embraced in the meta-analysis. Sensitivity analysis was also conducted by getting rid of any single literature to assess stability of the results. This study was conducted following the PRISMA guidelines and all data analysis was conducted with Stata 12.0 software (StatCorp, College Station, TX, USA).

\section{CONFLICTS OF INTEREST}

The authors declare no conflicts of interest.

\section{REFERENCES}

1. Rini BI, Campbell SC, Escudier B. Renal cell carcinoma. Lancet. 2009; 373:1119-32. https://doi.org/10.1016/s01406736(09)60229-4.

2. Chen W, Zheng R, Baade PD, Zhang S, Zeng H, Bray F, Jemal A, Yu XQ, He J. Cancer statistics in China, 2015. CA Cancer J Clin. 2016; 66:115-32. https://doi.org/10.3322/caac.21338.

3. Ljungberg $\mathrm{B}$, Bensalah $\mathrm{K}$, Canfield S, Dabestani S, Hofmann F, Hora M, Kuczyk MA, Lam T, Marconi L, Merseburger AS, Mulders P, Powles T, Staehler M, et al. EAU Guidelines on Renal Cell Carcinoma: 2014 Update. Eur Urol. 2015. https://doi.org/10.1016/j. eururo.2015.01.005.

4. Moch H, Artibani W, Delahunt B, Ficarra V, Knuechel R, Montorsi F, Patard JJ, Stief CG, Sulser T, Wild PJ.
Reassessing the current UICC/AJCC TNM staging for renal cell carcinoma. Eur Urol. 2009; 56:636-43. https:// doi.org/10.1016/j.eururo.2009.06.036.

5. Mantovani A, Allavena P, Sica A, Balkwill F. Cancerrelated inflammation. Nature. 2008; 454:436-44. https:// doi.org/10.1038/nature07205.

6. Aggarwal BB, Vijayalekshmi RV, Sung B. Targeting inflammatory pathways for prevention and therapy of cancer: short-term friend, long-term foe. Clin Cancer Res. 2009; 15:425-30. https://doi.org/10.1158/1078-0432.ccr-08-0149.

7. Grivennikov SI, Greten FR, Karin M. Immunity, inflammation, and cancer. Cell. 2010; 140:883-99. https:// doi.org/10.1016/j.cell.2010.01.025.

8. Templeton AJ, Ace O, McNamara MG, Al-Mubarak M, Vera-Badillo FE, Hermanns T, Seruga B, Ocana A, Tannock IF, Amir E. Prognostic role of platelet to lymphocyte ratio in solid tumors: a systematic review and meta-analysis. Cancer Epidemiol Biomarkers Prev. 2014; 23:1204-12. https://doi. org/10.1158/1055-9965.epi-14-0146.

9. Gu L, Li H, Chen L, Ma X, Li X, Gao Y, Zhang Y, Xie Y, Zhang X. Prognostic role of lymphocyte to monocyte ratio for patients with cancer: evidence from a systematic review and meta-analysis. Oncotarget. 2016; 7:31926-31942. https://doi.org/10.18632/oncotarget.7876.

10. Peng D, He ZS, Li XS, Tang Q, Zhang L, Yang KW, Yu XT, Zhang CJ, Zhou LQ. Prognostic value of inflammatory and nutritional scores in renal cell carcinoma after nephrectomy. Clin Genitourin Cancer. 2017. https://doi.org/10.1016/j. clgc.2017.04.001.

11. Ishihara H, Kondo T, Yoshida K, Omae K, Takagi T, Iizuka $\mathrm{J}$, Tanabe K. Effect of systemic inflammation on survival in patients with metastatic renal cell carcinoma receiving second-line molecular-targeted therapy. Clin Genitourin Cancer. 2017. https://doi.org/10.1016/j.clgc.2017.01.018.

12. Chrom P, Stec R, Bodnar L, Szczylik C. Incorporating neutrophil-to-lymphocyte ratio and platelet-to-lymphocyte ratio in place of neutrophil count and platelet count improves prognostic accuracy of the international metastatic renal cell carcinoma database consortium model. Cancer Res Treat. 2017. https://doi.org/10.4143/crt.2017.033.

13. Xia WK, Wu X, Yu TH, Wu Y, Yao XJ, Hu H. Prognostic significance of lymphocyte-to-monocyte ratio and CRP in patients with nonmetastatic clear cell renal cell carcinoma: a retrospective multicenter analysis. Onco Targets Ther. 2016; 9:2759-67. https://doi.org/10.2147/ott.s101458.

14. Park TJ, Cho YH, Chung HS, Hwang EC, Jung SH, Hwang JE, Bae WK, Kim JW, Heo SH, Hur YH, Jung SI, Kwon DD. Prognostic significance of platelet-lymphocyte ratio in patients receiving first-line tyrosine kinase inhibitors for metastatic renal cell cancer. Springer Plus. 2016; 5:1889. https://doi.org/10.1186/s40064-016-3592-4.

15. Hu H, Yao X, Xie X, Wu X, Zheng C, Xia W, Ma S. Prognostic value of preoperative NLR, dNLR, PLR and CRP in surgical renal cell carcinoma patients. World J Urol. 2016. https://doi.org/10.1007/s00345-016-1864-9. 
16. Gu L, Ma X, Xie Y, Li H, Wang L, Chen L, Zhao W, Zhang Y, Zhang X. Pretreatment lymphocyte to monocyte ratio is an independent prognostic factor in metastatic clear cell renal cell carcinoma. Clin Genitourin Cancer. 2016. https:// doi.org/10.1016/j.clgc.2016.12.001.

17. Gu L, Ma X, Li H, Chen L, Xie Y, Zhao C, Luo G, Zhang X. Prognostic value of preoperative inflammatory response biomarkers in patients with sarcomatoid renal cell carcinoma and the establishment of a nomogram. Sci Rep. 2016; 6:23846. https://doi.org/10.1038/srep23846.

18. Lucca I, de Martino M, Hofbauer SL, Zamani N, Shariat SF, Klatte T. Comparison of the prognostic value of pretreatment measurements of systemic inflammatory response in patients undergoing curative resection of clear cell renal cell carcinoma. World J Urol. 2015; 33:2045-52. https://doi.org/10.1007/s00345-015-1559-7.

19. Gunduz S, Mutlu H, Tural D, Yildiz O, Uysal M, Coskun HS, Bozcuk H. Platelet to lymphocyte ratio as a new prognostic for patients with metastatic renal cell cancer. Asia Pac J Clin Oncol. 2015; 11:288-92. https://doi. org/10.1111/ajco.12358.

20. Chang Y, Fu Q, Xu L, Zhou L, Liu Z, Yang Y, Lin Z, Xu J. Prognostic value of preoperative lymphocyte to monocyte ratio in patients with nonmetastatic clear cell renal cell carcinoma. Tumour Biol. 2016; 37:4613-4620.

21. Chang Y, An H, Xu L, Zhu Y, Yang Y, Lin Z, Xu J. Systemic inflammation score predicts postoperative prognosis of patients with clear-cell renal cell carcinoma. Br J Cancer. 2015. https://doi.org/10.1038/bjc.2015.241.

22. Keskin S, Keskin Z, Taskapu HH, Kalkan H, Kaynar M, Poyraz N, Toy H. Prognostic value of preoperative neutrophil-to-lymphocyte and platelet-to-lymphocyte ratios, and multiphasic renal tomography findings in histological subtypes of renal cell carcinoma. BMC Urol. 2014; 14:95. https://doi.org/10.1186/1471-2490-14-95.

23. Hutterer GC, Stoeckigt C, Stojakovic T, Jesche J, Eberhard K, Pummer K, Zigeuner R, Pichler M. Low preoperative lymphocyte-monocyte ratio (LMR) represents a potentially poor prognostic factor in nonmetastatic clear cell renal cell carcinoma. Urol Oncol. 2014; 32:1041-8. https://doi. org/10.1016/j.urolonc.2014.04.001.

24. Fox P, Hudson M, Brown C, Lord S, Gebski V, De Souza P, Lee CK. Markers of systemic inflammation predict survival in patients with advanced renal cell cancer. Br J Cancer. 2013; 109:147-53. https://doi.org/10.1038/bjc.2013.300.
25. Dirican A, Kucukzeybek Y, Somali I, Erten C, Demir L, Can A, Bahriye Payzin K, Vedat Bayoglu I, Akyol M, Koseoglu M, Alacacioglu A, Oktay Tarhan M. The association of hematologic parameters on the prognosis of patients with metastatic renal cell carcinoma. J BOUN. 2013; 18:413-9.

26. Templeton AJ, McNamara MG, Seruga B, Vera-Badillo FE, Aneja P, Ocana A, Leibowitz-Amit R, Sonpavde G, Knox JJ, Tran B, Tannock IF, Amir E. Prognostic role of neutrophil-to-lymphocyte ratio in solid tumors: a systematic review and meta-analysis. J Natl Cancer Inst. 2014; 106:dju124. https://doi.org/10.1093/jnci/dju124.

27. Gu L, Li H, Gao Y, Ma X, Chen L, Li X, Zhang Y, Fan $\mathrm{Y}$, Zhang $\mathrm{X}$. The association of platelet count with clinicopathological significance and prognosis in renal cell carcinoma: a systematic review and meta-analysis. PLoS One. 2015; 10:e0125538. https://doi.org/10.1371/journal. pone. 0125538 .

28. Heng DY, Xie W, Regan MM, Warren MA, Golshayan AR, Sahi C, Eigl BJ, Ruether JD, Cheng T, North S, Venner P, Knox JJ, Chi KN, et al. Prognostic factors for overall survival in patients with metastatic renal cell carcinoma treated with vascular endothelial growth factor-targeted agents: results from a large, multicenter study. J Clin Oncol. 2009; 27:5794-9. https://doi.org/10.1200/jco.2008.21.4809.

29. Orellana R, Kato S, Erices R, Bravo ML, Gonzalez P, Oliva B, Cubillos S, Valdivia A, Ibanez C, Branes J, Barriga MI, Bravo E, Alonso C, et al. Platelets enhance tissue factor protein and metastasis initiating cell markers, and act as chemoattractants increasing the migration of ovarian cancer cells. BMC Cancer. 2015; 15:290. https://doi.org/10.1186/ s12885-015-1304-z.

30. Hoffmann TK, Dworacki G, Tsukihiro T, Meidenbauer N, Gooding W, Johnson JT, Whiteside TL. Spontaneous apoptosis of circulating $\mathrm{T}$ lymphocytes in patients with head and neck cancer and its clinical importance. Clin Cancer Res. 2002; 8:2553-62.

31. Dunn GP, Old LJ, Schreiber RD. The immunobiology of cancer immunosurveillance and immunoediting. Immunity. 2004; 21:137-48. https://doi.org/10.1016/j. immuni.2004.07.017.

32. Tierney JF, Stewart LA, Ghersi D, Burdett S, Sydes MR. Practical methods for incorporating summary time-to-event data into meta-analysis. Trials. 2007; 8:16. https://doi. org/10.1186/1745-6215-8-16. 